\title{
Transforming Urban Economy with 'Eds and Meds': Inspirations from the Texas Medical Center (TMC)
}

\author{
Xuanyi Nie \\ Graduate School of Design, Harvard University, Cambridge, USA \\ Email address: \\ niexuanyi@gmail.com \\ To cite this article: \\ Xuanyi Nie. Transforming Urban Economy with 'Eds and Meds': Inspirations from the Texas Medical Center (TMC). Urban and Regional \\ Planning. Vol. 4, No. 4, 2019, pp. 136-143. doi: 10.11648/j.urp.20190404.12
}

Received: November 1, 2019; Accepted: November 25, 2019; Published: December 3, 2019

\begin{abstract}
Globalization has transformed urban economy from production of materials to production of knowledge. The knowledge economy in the cities in return demands an increasingly skilled and educated workforce. Understanding that cities are and will continue to be the foundation for economic growth, one immediate challenge is to look for economic engines that help this transformation in cities. At the same time, cities in the US offered a unique perspective through 'Eds and Meds'. Due to breakthroughs in medical research and the growing density of cities, hospital campuses are demanded to expand in size and diversity of programs. The resulting campus as an urban typology integrates medical care, medical schools and research institutes. Anchoring upon service-industry, this typology promotes urban development through increased level of economic activities related to healthcare industry. Examples of such strategy can be widely found across the US geography. This paper identifies the Texas Medical Center (TMC) in Houston as the case study to further examine the underlying mechanisms of such typology. The case study dives into the history of the development of the TMC, then, drawing upon statistics, theorizes the critical foundations for the success of TMC through the principles of agglomeration effects. Based on these findings from the Texas Medical Center, this paper also outlines recommendations on key elements essential for adopting 'Eds and Meds' for urban development.
\end{abstract}

Keywords: Urban Economy, Hospital, Eds and Meds, Economic Development, Agglomeration Effects

\section{Introduction}

Globalization has transformed urban economy from production of materials to production of knowledge. The knowledge economy in the cities in return demands an increasingly skilled and educated workforce. Understanding that cities are and will continue to be the foundation for economic growth, one immediate challenge is to look for engines that help this transformation. Meanwhile, medical and higher education institutions have become centerpieces of urban economies therefore need more attention in research. Economic development is typically defined to encompass profit-making enterprises. However, although the great majority of higher education and medical institutions are nonprofits, they have unique characteristics that add value beyond just profit-making.

The phenomenon of a hospital campus evolving into a 'city inside city' is not new. Due to breakthroughs in medical research and the growing density of cities, hospital campuses are demanded to expand in size and diversity of programs. The resulting urban forms, referred here as 'Eds and Meds', typically integrate the functions of medical (patient care \& clinics), educational (medical school and training facilities) and research (labs and office space). The Texas Medical Center (TMC) represents a typical 'Eds and Meds' campus. This typology promotes economic development with three instruments. First of all, the educational component promotes innovation by training analysts, producing new knowledge for local businesses thereby increasing productivity and attracting firms. Secondly, hospitals and universities employ large numbers and purchase large amounts of goods and services from the local marketplace. These increase wages and employment opportunities for local residents. Thirdly, it opens up new possibilities for healthcare communities, creating space for other uses, including residential, hospitality, and retail, which attract developers thereby appreciating value of surrounding properties. Over time, a new city is born out of these migrating populations driven by healthcare industry.

In an era increasingly dependent on knowledge-based industries, 'Eds and Meds'becomes more desirable in cities. 
Being a relatively new field, scholars such as Carolyn Adams and Timothy Bartlik have only started paying attention to this type of transformation in urban economy since mid 2000s. This topic has been studied as a general phenomenon while little in-depth research has been done on individual cases such as the TMC, which is the largest 'Eds and Meds' complex in the US. Although Junxiang Yin wrote an article on the TMC in 2015, it focused more on the history and policy aspects, little attention is given to the economic principles behind. Hoping to expand research in this field, this paper studies this specific urban phenomenon by firstly going through the trends and conditions of 'Eds and Meds' across the US, then using the TMC case to further examine its history, economic principles behind, and its contribution to economic development. The significance of this research is to help policy makers realize that the sometimes overlooked 'Eds and Meds' institutions could be the new economic engines in contemporary cities.

\section{2. 'Eds and Meds' Economy in the US}

This development strategy is widely used across American cities. Data shows that, for US metropolitan regions, the presence of high-quality doctoral programs in life sciences and engineering is positively associated with employment growth [1]. Bartlik and Erickceck from the Brookings Institution examine the impact on metropolitan economic development to expand healthcare and higher education institutions from four impacts [2]. Expanding eds and meds brings in new income to a metropolitan area by enabling those institutions to serve more students or patients who live elsewhere and who would not otherwise spend money in the metropolitan area. Expanding eds raises residents' earnings by improving their skills as residents are more likely to earn college degrees and remain in the area to work. Expanding meds is likely to encourage other employers in a metropolitan area to pay higher wages as healthcare pays higher than average wages regardless of workers' skills and demographic characteristics. Expanding research can lead to the creation of new businesses in a metropolitan area and improve the performance of existing businesses thus spurs metropolitan economic development.

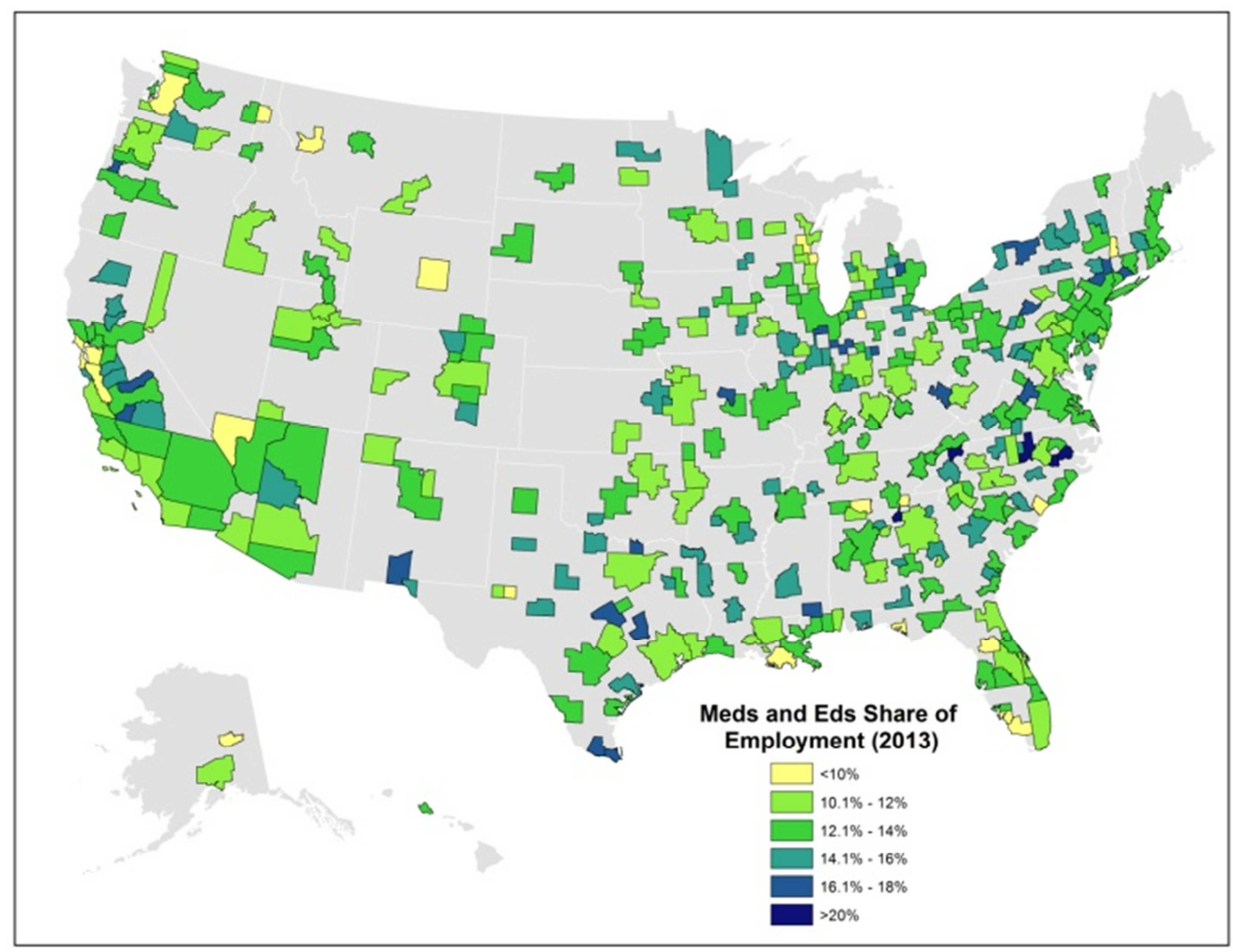

Figure 1. Levels of employment in the education and health care sectors across 350-plus metropolitan regions in the US.

Harkavy and Zuckerman found that by 2000 , in four of the cities - Washington, Philadelphia, San Diego, and Baltimore — 'Eds and Meds' campuses account for more than half of the jobs generated, while nearly 550,000 , or $35 \%$ of the 1.6 million people who work for the top ten private employers in the largest 20 U.S. cities are employed by 'Eds and Meds' campuses [3]. Shown in Fgure 1, Charlotta Mellander and Zara Matheson from the Martin Prosperity Institute (MPI) found that across the nation in 2013, eds and meds make up roughly $13 \%$ of total employment in U.S. metros. But the range is considerable. Eds and meds employment ranges from roughly $4 \%$ with the lowest share to nearly $30 \%$ in the metro with the highest share [4]. Eds and meds make up $17.32 \%$ of employment in New Haven, Connecticut; $16.01 \%$ in Rochester, New York; 13.94\% in Boston, Massachusetts; $13.88 \%$ in Providence, Rhode Island; and $13.58 \%$ in 
Baltimore, Maryland. Some of these metros-like New Haven, Providence, and Boston-have world-class clusters of medical and higher-ed institutions and are therefore among the places most likely to benefit from greater competition and clustering of these industries. Others have solid but not spectacular institutions that may enable them to survive if in shrunken form.

Carolyn Adams did a comparative study between Pittsburg and Philadelphia - the adoption of meds and eds is an inevitable alternative of deindustrialization as cities transition from manufacturing to knowledge economy [5]. As the research development on biotechnology plays a significant economic pay-off building on the nonprofit institutions of universities and science centers, it is important for the government to realize the potential of the nonprofit institutions, to encourage collaborations rather than competitions. At the same time the university and research components are particularly indispensable to the potency of eds and meds. Ehlenz, Birch and Agness from Penn Institute of Urban Research collected a range of cases on cities with anchor institutions including Philadelphia, Boston, Chicago, New York and Baltimore to study ways urban universities invest in revitalization and innovation in their neighborhoods [1]. It is important for anchoring institutions to expand their missions beyond campus and align their interests with the interests of the larger communities such as investment in housing, commercial development and open space to unleash the full potential of eds and meds development.

\section{The History of the TMC}

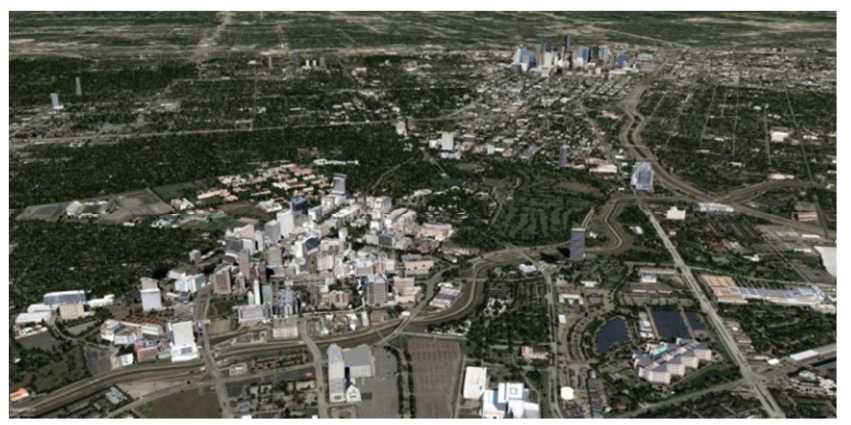

Figure 2. Overlooking TMC and downtown Houston.

The TMC was conceived after the death of Monroe Dunaway Anderson, a banker and cotton trader who founded a successful cotton merchandising firm called Anderson, Clayton and Co. In 1936 he founded the M.D Anderson Foundation with $\$ 300,000$ for the vision of a medical center consists of many hospitals, academic institutions and various supporting organizations - 'a city of medicine such as envisioned by Asclepius in ancient Greece' [6]. Upon Anderson's death in 1939, the foundation, as the principal beneficiary of his estate, received over $\$ 19,000,000$ in funding. In 1941, Texas Governor Lee O'Daniel signed House Bill 268, which authorized a state cancer research hospital and appropriated $\$ 500,000$ towards its construction. The Forty-seventh Texas Legislature approved the establishment of the Texas State Cancer Hospital and Division of Cancer Research.

This largest comprehensive cancer center in the world was attracted by free land and funding pledged by the trustees of Anderson Foundation together with the Houston Chamber of Commerce. In 1942 the University of Texas Board of Regents accepted the offer from the M. D. Anderson Foundation to provide temporary facilities, furnish a permanent site, and match the state's \$500,000 appropriation if the new institution would be built in Houston [7]. The UT regents also voted to name the hospital for Monroe Dunaway Anderson. In the same year the Houston physician Ernst W. Bertner was appointed acting director of the hospital who invited the first five staff members, four of them were scientists borrowed from the UT Medical Branch at Galveston to conduct research projects in biochemistry and biology. They all worked in remodeled quarters on the family estate known as the Oaks, originally owned by Capt. James A. Baker, who had bequeathed it to Rice Institute.

The vision was that the TMC would grow on land purchased, and then made available without cost, to institutions so that they would come and build here. Seed money would also be provided and people from all over Texas would be asked to help to fund it. The trustees arranged a referendum election which permitted the trustees to purchase the original 134-acre campus next to Hermann Hospital for $\$ 3,000$ per acre, totaling $\$ 402,000$, for the new cancer hospital to use as temporary headquarters to start research projects and see patients [8]. A corporation named 'TMC Corporation Inc' was then created in charge of the operation including attracting institutions and many day-to-day activities of the private streets, private utilities, private police, a newspaper, a very large parking operation.

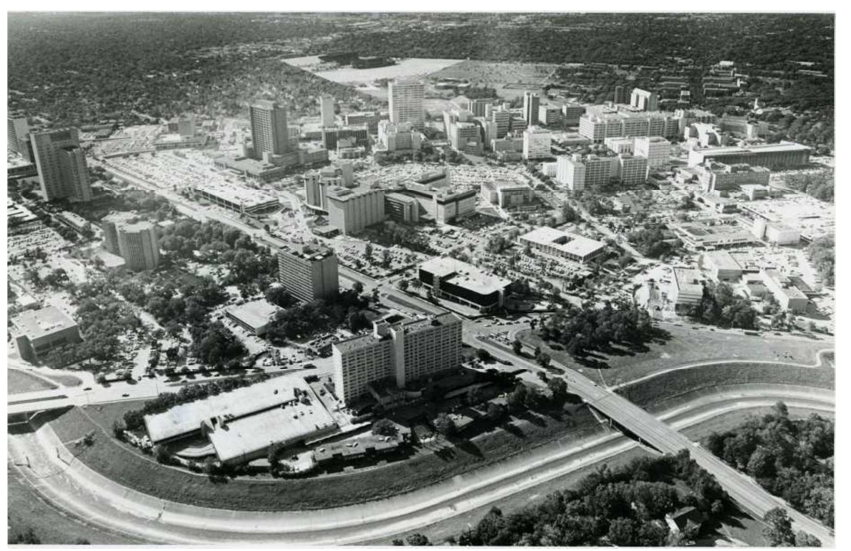

Figure 3. The TMC in 1980. Courtesy of the Houston Chronicle.

Soon in 1943 Baylor University College of Medicine was convinced by the corporation to moves from Dallas to Houston to meet the need for a medical school. In 1948 the M. D. Anderson Foundation donated twenty-two acres of wooded land in the newly named The TMC to build a permanent hospital. Construction of the original 310-bed facility began on December 20, 1950 [7]. The name The TMC itself reflects the bigger ambition that this complex is 
made for people from Texas not just I Houston. Later in the 1950s, the Dental Branch of UT, Texas Children's Hospital, the Methodist Hospital and St. Luke's Episcopal Hospital all broke ground. Their success served as a catalyst, driving others to join the TMC's community of non-profit health care institutions. By 1954, The TMC corporate offices were created to oversee land distribution and develop the common areas for the new medical city.

Aerial photographs in Figure 4 show that the original woodland was covered between 1944 and 1953, while most of the construction took place between 1953 and 1978. V50 years after the initial plan, by 1992, fourteen hospitals and six university systems comprised the TMC, occupying over 670 acres of land. Combined operating budgets of the TMC institutions for 1991 were over $\$ 4$ billion, more than the combined operating budgets of the City of Houston and Houston Independent School District. There are 11,200 students enrolled in regular coursework in the TMC and 75,000 persons attended short courses or continuing education programs. During 1991, \$437 million was pledged through grants for research projects; with $\$ 353$ million received from outside sources to fund research. In 1992, the TMC institutions had [6]:

a) 52,911 employees (less than 5,000 are part-time)

b) $3,087,664$ patient visits a year - 237,161 inpatient and $2,850,503$ outpatients.

c) 6,694 licensed hospital beds and 407 bassinets

d) 37,060 parking places, of which 20,201 were TMC owned or operated, 14,448 are member institutions owned or operated, and 2,500 were under design.

The momentum of growth continues. The years from the late 1990 s to 2010 were a time of dynamic growth and booming construction in the TMC. The TMC added physical plant and parking space through its acquisition of the Nabisco plant and construction of the McGovern Commons. In 1999, Nabisco announced that it would phase out its fifty-year-old Houston plant on Almeda Road, laying off some 425 employees as part of an effort to reduce excess manufacturing capacity in the United States [9]. The acquisition and renovation of the Nabisco plant added badly needed parking and a spacious, solid building whose wide-open interior was perfect for institutions that needed more space they could customize for research, education, and other activities. In addition, the institutions that used the space had personnel under the same roof with other institutions, providing opportunities for collegiality and possibly future collaborations. The TMC leased space in the building to the institutions for a very reasonable rate, which was mutually beneficial in that it provided income for the $\mathrm{TMC}$ and it helped the institutions find precious space at a cost-effective rate in an otherwise very pricey part of town.

All of the building construction in the TMC that began during the late 1990s and continued into the next decade provided a significant boost for Houston's economy. The individual institutions added more space as construction of new facilities continued, with a brief slow-down during the economic recession at the end of 2008. The TMC rebuilt and fortified crucial infrastructure, replacing all of the private streets in the complex and improving drainage, utilities, sidewalks, and even much of the landscaping. By 2014, the TMC had 54 member institutions, composed of 27 government agencies and 27 not-for-profit health care facilities. Today, the TMC encompasses over 50 million developed square feet and $\$ 3$ billion in construction projects underway, offering the home to the world's largest children's hospital and the world's largest cancer hospital with 10 million patient visits per year and over 9,200 total patient beds [10]. With a sprawling campus that receives over 160,000 visitors daily, the TMC alone ranks as the 8th-largest downtown business district in the United States, right after Philadelphia and Seattle [8].

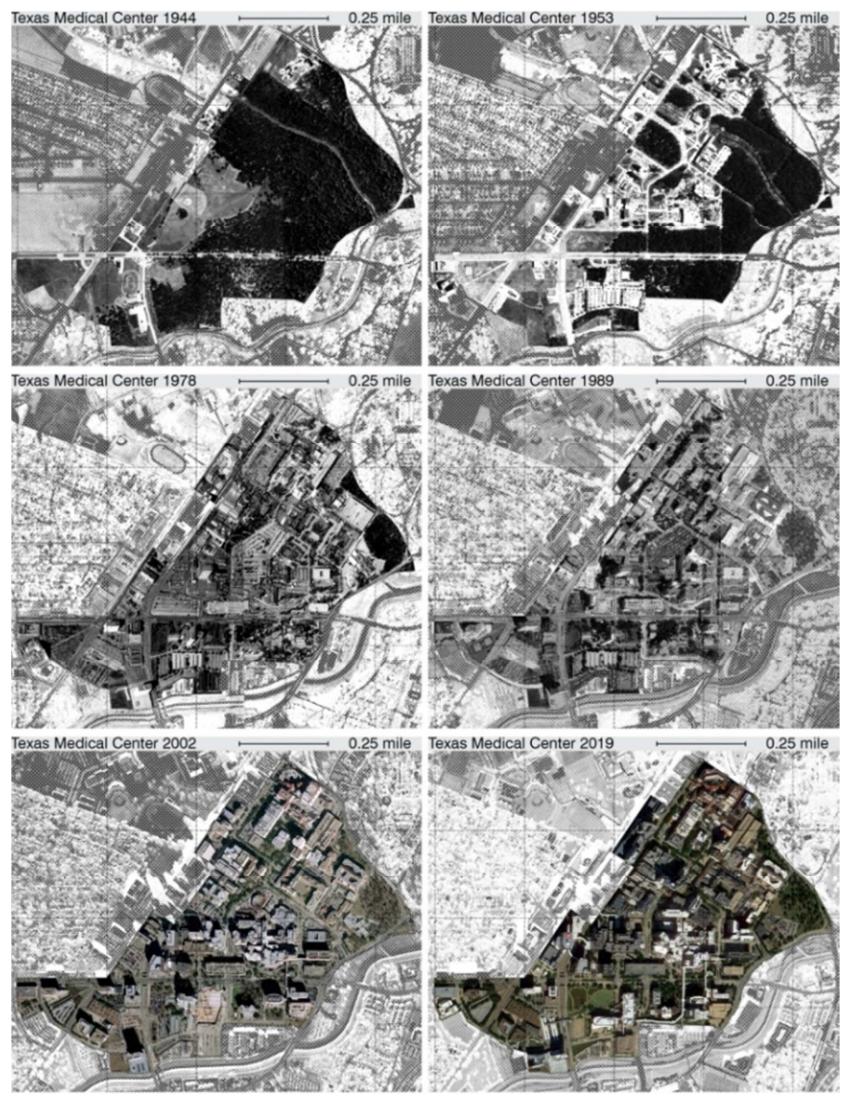

Figure 4. TMC campus 1944-2019.

Based on the historical study, of course this tremendous success of The TMC should be attributed to Anderson and his legacies. But principles of agglomeration economy can provide for more intricate rationale behind the escalating scale of built area and economic activities of the TMC, as well as other similar campuses. Agglomeration economy in convention is believed to have amplifying effects which increases the scale of economic benefits. However it is also true that agglomeration can help reduce costs in economic activities. The next session of this paper discusses the principles of agglomeration behind TMC from both amplifying effects and cost reductions related to economic activities. 


\section{Economic Principles of TMC}

\subsection{Anchoring Effect}

The agglomeration economics in convention is believed to attract new businesses and enhance existing productivity. This enhancement in the TMC an be analyzed through three lenses: the anchoring effect, the multiplying effect and the innovating effect. Anchoring effect is a result of the density of population and economic activities. In the case of the $\mathrm{TMC}$, it begets from the free land by the Anderson Foundation to attract the first member institutions. The largest institution, UT M. D Anderson Cancer center, acted as the center of economic gravity attracting talents and other institutions. They seek for opportunities to expand production through establishing collaborative relationships with anchoring institutions in biomedical and pharmaceutical research projects that has potential market returns. Other institutions were attracted by the large volume of population (patients and employees) to expand consumption in supporting industries such as retail and hospitality. This effect escalates in scale that each of the institution attracted by the original anchoring institution would become part of the overall mass of the TMC, further attracting more institutions, similar to an avalanche, but in a positive way. This anchoring effect will scale on itself, taking advantage of the agglomerated institutions and economic activities, which eventually demand to expand to a larger territory.

Table 1. Economic Scales in Houston, Manhattan and Chicago.

\begin{tabular}{llll}
\hline & TMC & $\begin{array}{l}\text { Lower } \\
\text { Manhattan }\end{array}$ & Ratio \\
\hline Total Land Area & $5.4 \mathrm{~km}^{2}$ & $2.35 \mathrm{~km}^{2}$ & 2.30 \\
Building Space & $4.65 \mathrm{~km}^{2}$ & $8.65 \mathrm{~km}^{2}$ & 0.54 \\
Employment & 106,000 & 227,100 & 0.47 \\
GDP & $\$ 25 \mathrm{billion}$ & $\$ 62.3 \mathrm{billion}$ & 0.40 \\
Building Density (FAR) & 0.86 & 3.68 & 0.23 \\
Job Density (Land Area) & $19,630 / \mathrm{km}^{2}$ & $96,700 / \mathrm{km}^{2}$ & 0.20 \\
Job Density (Built Area) & $22,800 / \mathrm{km}^{2}$ & $26,300 / \mathrm{km}^{2}$ & 0.87 \\
\hline
\end{tabular}

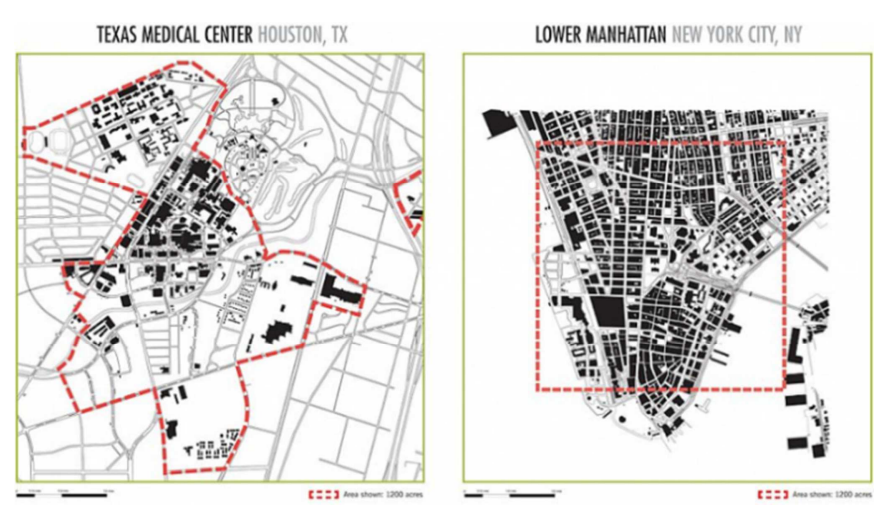

Figure 5. The TMC and Lower Manhattan. Produced by SOM.

Table 1 collects data on the comparison between the TMC (2019) and lower Manhattan in NYC (2015) [11]. It shows that although the job density in LM is much higher than in TMC per land area, the job density per built area of the TMC is very close to the density in LM. This suggests that the density of economic activities happening inside the buildings resemble the density of office buildings in lower Manhattan. As TMC is a complex mixed with medical, educational, and research components, the capacity of job creation in such a typology is equivalent to office buildings in Manhattan. However, due to zoning or spatial regulations (such as the height restrictions set by zoning code and height of buildings fixed60 years ago), the density of buildings in this area is no mach to the density of buildings in LM. But once the building density (0.86) of the TMC being equivalent to the density of LM (3.68), statistically the employment would double LM and the GDP would exceed LM by $70 \%$. This explains the stamina of growth in the TMC even 70 years after the construction began - the demand is constantly present, driving the campus to expand in size and density.

\subsection{Multiplying Effect}

Multiplying effect is powerful in economic return and job creation. The general principles behind were explained by Jane Jacobs with the formula of job division. She argued that existing divisions of labor multiply into more divisions of labor by intervening added activities that yield up new sums of work to be divided, expressed in the $\mathrm{D}+\mathrm{A} \rightarrow \mathrm{nD}$ formula [12]. This principle works at a city scale, but is also true for the TMC where all sorts of economic activities take place daily. Jobs can be created from net number increase due to demand, division of labor market due to specialization and service associated with the new jobs. On one hand, funded R\&D projects and the increasing demand of medical care of the population require new jobs at the medical center to fulfill the use of the fund and to meet the market demand. On the other hand, the increasing demand for quality of care from the inpatient and outpatient services, accompanied with rapidly advancing medical technologies, require job duties of the employees to be more specialized. This specialization in the labor market will create more jobs. Furthermore, the advanced activities in medical sector also require other relatively fundamental economic activities in service sector to support the operation of the TMC. Retails, hospitality, and catering can bring visible jobs to the community, while consumption of goods, both medical and service goods, at the TMC would demand more invisible jobs in the production chains, at places beyond the territory of the TMC.

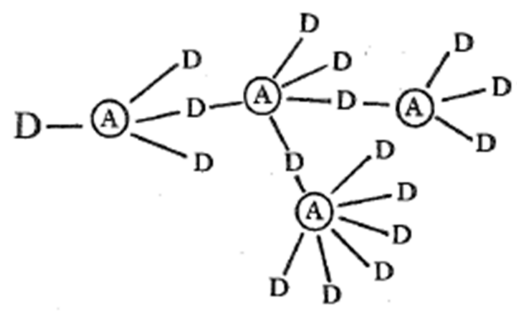

Figure 6. $D+A \rightarrow n D$ formula for job division.

These general principles are backed by a research done by Yin showing that based on statistics in 2015, per $\$ 1$ investment in the TMC brings $\$ 1.44$ return and per 1 new job 
in the TMC brings 1.3 more jobs for the community [13]. This substantiates the argument of multiplying effect in both job creation and economic return. But certain caution should be given to these statistical results. John Siegfried and Andrew Zimbalist argued that a substitution effect can exist when measuring growth in labor market that the $\mathrm{x}$ number of jobs brought by a facility is not necessarily the net growth of jobs - the effect could simply be replacing some of the jobs in the local community with jobs that require other sets of techniques and skills [14]. Nevertheless the TMC generated more than 106,000 jobs by 2019 , counting for $3.34 \%$ of the total 3169,300 jobs in Houston Metropolitan Area. By July 2019 in Houston Metropolitan Area there are 401,600 jobs in education and healthcare services, and the jobs from the Texas Medical Canter account for 26.4\% from that pool [15]. The 410,600 employments include the large amount of jobs from educational institutions such as Rice University and others. Lessing that number would only make the contribution of jobs at the TMC greater.

Table 2. Land Use Distribution in the TMC.

\begin{tabular}{lllll}
\hline & Hospital & Education & Office & Retail \\
\hline Percentage & $30.62 \%$ & $13.61 \%$ & $40.79 \%$ & $2.22 \%$ \\
\hline
\end{tabular}

Source: http://arcgis02.h-gac.com/RLUIS/

One key element to multiplying effect in job creation and economic return is the diversification in programs. Data from the Houston Regional Land Use Information shows that although named The Texas Medical Center, this area significant portion of office space $(40.79 \%)$ even more than the medical space $(30.62 \%)$, which is accompanied with some retail space $(2.22 \%)$ aside of the hospital and education programs. Many of the office spaces are owned by or leased to sectors related to healthcare services such as the Memorial Hermann Medical Plaza, a 1,250,000 ft2 office building, created through a partnership between Mischer Healthcare and Memorial Hermann Healthcare System, who provides for physician and examination use. Hospitality such as the Houston Marriott Medical Center, a 301,000 sqf hotel, is another use to host patients' family or experts traveling to the TMC. Interestingly some spaces are also rented to companies not professionally related, such as the Jewel Box (a company offers jewelry services) is located on the second floor of the $1,270,000$ sqf Houston Methodist Hospital - Smith Tower. This is a typical example of retailing industry taking advantage of the market (population of both patients and employees). This diversification in programs is crucial for maintaining multiplying effect since diversified programs would encourage different economic activities which in return require people with different skills thereby expand the labor pool for employment. Contrary to only offering monotype jobs, a diversified job market creates more opportunities for the local communities.

\subsection{Consolidating Effect}

Similar in nature but different in mechanism, consolidating effect does not amplify the result but reduces costs in economic activities. Core ideas of agglomeration economies include people choosing to locate close to each other to reduce transportation cost, and locating firms in a single location instead of spreading out can save cost too. On one hand, a condensed campus saves time for information and material exchange, ensuring frequency of activities. Locating research, medical and educational institutions close to each other saves the time cost for employees to travel among different institutions. New-born from the Texas Children's Hospital can be transferred to and treated at the Houston Methodist Hospital next door. Physicians and doctors from different institutions can also move freely for consultations. Students from medical school can easily intern in a medical institution. Anchoring, multiplying and innovating effects can happen only when frequent information exchange is guaranteed, and proximity among these institutions significantly reduces time cost to travel. The condensed campus of the TMC performs similarly to the downtown district of Houston - when time is money, institutions need to agglomerate to reduce the cost.

On the other hand, a condensed campus also saves spatial cost for the sharing of public goods. These public goods can include public spaces such as communal space and green space, infrastructural services such as road and parking, public transportation such as the TMC shuttles, and utilities such water and electricity. Managing, operating and maintaining such public goods translate into costs. From the demand side, with institutions close to each other, these public goods can be much more effectively (higher frequency of use) and easily (larger volume of users) accessed by the employees and patients, even residents around. From the supply side, delivering multiple public projects for scattered campuses takes longer time to acquire permissions and turns into more opportunity and interest costs, but a condensed campus avoids such costs in providing these public goods. Furthermore, when these public goods are located together in one campus instead of being scattered across the city, cost in the management, operation and maintenance of the campus and its public goods can be greatly reduced since less time, work and labor force are needed.

\subsection{Innovating Effect}

The sometimes overlooked by actually most important one is the innovating effect on the human capital. One core idea of agglomeration economics is that in dense areas, ideas spread between people. Consequently, people become more productive when they can learn from each other. In modern society, exchange of knowledge takes place not only at schools, but also in work space. This has been proven true in the cases of route 128 and Silicon Valley that condensed high-quality human capital enhanced collaboration among diverse groups, as well as promoting competition among individuals as a stimulus for productivity [16]. To ensure the 
power of innovating effects, two prerequisites should be met: top talents and frequent of knowledge exchange. Top talents make sure that the most advanced cutting-edge technology, research methodology or simply thoughts could be brought in and spread, and frequent knowledge exchange ensures that, taking advantage of the density, the information is constantly spread, tested and feedback among people.

The success of the TMC is assured by the TMC 50 Year Master Plan in 1999 that identified nine objectives, including human-centered guidelines such as 'provide the highest quality learning environment' and 'reflect a commitment to multidiscipline collaboration, institutional partnerships, and the exchange of ideas in research and education' [8]. The TMC has dedicated to bringing in world-known talents including Michael E. DeBakey from Baylor College of Medicine who performed the world's first coronary artery bypass procedure at the Methodist Hospital in 1964, and Dr. Denton Cooley who performed one of the first heart transplants in the U.S. at Texas Heart Institute [17]. These human and talent-oriented principals set the infrastructural step stones for the future blossom of the TMC.

\section{Recommendations}

While the principles of agglomeration economics can explain the success of the TMC both in its formation and its contribution to regional economy, the market itself will not take care of everything. Specific policy and management strategies should be provided to back and tailor the applicability of the TMC typology and the 'Eds and Meds' model of urban development. This session discusses several recommendations when applying the 'Eds and Meds' model based on the findings from TMC. The first recommendation is the provision of government incentives. The TMC would have not emerged had the state government of Texas not granted the M.D Anderson Cancer Center to the 134-acre land in the first place. The M.D Anderson Cancer Center acted as the anchoring institution that attracts other medical and educational institutions to the TMC. But the cancer center and market economy itself could not have fueled the development singlehandedly - the government has been putting tremendous support for the TMC. Public and personal monetary support to the TMC was tremendous - the TMC received a state grant of $\$ 500,000$ when it was established, a $\$ 300$ million federal support in 2015, tax abatement and many personal donations including one $\$ 5$ million donation in 2003 [13]. With this influx of capital, the spatial construct of the TMC can be imagined as a 'shelter' for capitals.

The second recommendation is density and time. All of the anchoring, multiplying, consolidating and innovating effects rest upon the premise of density, specifically of economic activities. Shown in the previous analysis that the density of the TMC is far less than the density of lower Manhattan, but one should understand that a medical campus is different from a downtown area in nature. Zoning and building regulations are different, so outpatient buildings and inpatient towers cannot be built too tall while they are required to have certain amount of public spaces en ensure safety as well as human comfort. But at the same time similar to a downtown district, density should be assured when economic activities are frequent, such as in the research and office areas. Meanwhile, is it worth noticing that the construction of the TMC beganabout 70 years ago in early 1940s, and the expansion and construction continues today. Although most of the core campus was constructed between 1950s and 1970 s, it still took two decades. In contemporary cities, sometimes due to political demands or favors to short-term investments in capital market, a typology of such is expected to be completed in a matter of years. It is important for the decision makers and relative stakeholders to realize that healthcare-related industry is in nature long-term on return, so when making a master plan of such typology, phasing is crucial as it allows the supply to catch up with demand incrementally while leaving rooms for future adjustments.

The third recommendation is designing effective organizational structures to reduce transaction costs, especially among different institutions. Understanding that the success of the TMC as an urban typology is also anchored on frequent exchanges of materials and information, specifically knowledge and technology, creating a healthy eco-system for innovation is essential to this mechanism. It encourages interdisciplinary collaborations under the given funds, and a collaborative environment reduces the internal cost (such as malign competition) to share funds, talents, research outcomes and technologies among different institutions. In doing so the TMC launches the Innovation Institute in 2014, the first of five institutes, developed to foster collaboration across the member institutions [17]. Moreover, the Anderson Foundation, the trustees, the management corporation, and the 22 professional committees reduced the administrative cost through designing an effective system to allocate funds to users. Employing effective management teams also reduces internal costs.

\section{Conclusion}

While principles of agglomeration economics apply on city-scale phenomenon, it is also applicable for the TMC, a condensed campus paralleling a city-within-city. This paper discusses the formation and success of the TMC through the lens of agglomeration economics. This paper finds that the agglomeration effect in the TMC is believed to be able to anchor institutions and industries, multiply on employment opportunities and economic returns, consolidate space to reduce costs, and encourage innovations. These effects together made the TMC a powerful economic engine. It is true that the success of the TMC can be partially attributed to the market and the demand in Houston and the US, but this paper also argued that certain key elements need to be in place to ensure the full capacity of the 'Eds and Meds' development strategy, represented by the TMC.

Although agglomeration can happen through providing fundamental incentives that encourage anchoring and density, the full capacity of such mechanism is achieved only when 
several key foundations are rooted. Based on the findings from the TMC, the paper argues that the government should help both policy wise and monetary wise, the decision makers and stakeholders should understand the long-term nature in economic return of such a typology, and the managers and operators should learn to design effective organizational structures to encourage healthy collaboration and effective management. The success of TMC is not just a product of mere concentration of resources, but also a tailored combination of government initiatives, societal support, and calibrated management and operation. The inspiration is straightforward -urban phenomena are not just materialized economic resources and theoretical models. Management and intervention matter as well.

\section{References}

[1] Ehlenz, Megan M, Birch, Eugénie L and Agness, Brian. (2014). The Power of Eds\& Meds: Urban Universities Investing in Neighborhood Revitalization \& Innovation Districts. Philadelphia: Penn Institute for Urban Research.

[2] Bartlik, Timothy J and Erickceck, George. (2008). The Local Economic Impact of 'Meds and Eds': How Policies to Expand Universities and Hospitals Affect Metropolitan Economies. Brookings: Metropolitan Policy Programs.

[3] Harkavy, Ira, and Zuckerman, Harmon. (1999). Eds and Meds. Cities Hidden Assets. Washington: Brookings Institution Reports.

[4] Florida, Richard. "Where 'Eds and Meds' Industries Could Become a Liability." CITYLAB. Updated November 26, 2013. https://www.citylab.com/life/2013/11/where-reliance-eds-andmeds-industries-could-become-liability/7661/.

[5] Adams, Carolyn. (2003). The Meds and Eds in Urban Economic Development, The Journal of Urban Affairs, 25(5), 571-588.

[6] Wainerdi, Richard E., and Newcomen Society of the United States. Texas Medical Center. Newcomen Publication ; No. 1395. New York: Newcomen Society of the United States, 1993.
[7] Handbook of Texas Online, Mary Jane Schier, "UNIVERSITY OF TEXAS M. D. ANDERSON CANCER CENTER," accessed October 30, 2019, http://www.tshaonline.org/handbook/online/articles/kcu26.

[8] Orlando, Alex. "Building a City of Medicine: The History of the Texas Medical Center." TMC NEWS. Updated August 19, 2014. https://www.tmc.edu/news/2014/08/building-a-city-of-medici ne-the-history-of-the-texas-medical-center/.

[9] Kellar, William Henry, Barbara Bush, and Charles A. Lemaistre. Richard E. Wainerdi and the Texas Medical Center. College Station: Texas A\&M University Press, 2017.

[10] TMC. "Facts \& Figures". Medical Statistics. Updated $26^{\text {th }}$ April, 2019. https://www.tmc.edu/about-tmc/facts-and-figures/

[11] Surging Ahead: Lower Manhattan's Economic Revival and What It Means for New York. "Economic Growth and Opportunity: Building New York City's Future in Lower Manhattan.” DowntownNY. November 25, 2015. https://www.downtownny.com/reports/surging-ahead-lower-m anhattan $\% \mathrm{E} 2 \% 80 \% 99$ s-economic-revival-and-what-it-meansfor-new-york

[12] Jacobs, Jane. The Economy of Cities. Random House, 1969.

[13] Yin, Jun-xiang. "Regional Development of Economy and Society Investigation of Development Experiences of Texas Medical Center." Global Science, Technology and Economy Outlook 30, no. 07 (2015): 43-47.

[14] Siegfried, John, and Andrew Zimbalist. "The Economics of Sports Facilities and Their Communities." Journal of Economic Perspectives 14, no. 3 (2000): 95-114.

[15] Bureau of Labor Statistics (Houston Area Employment July 2019; accessed October 31, 2019) https://www.bls.gov/regions/southwest/news-release/areaempl oyment_houston.htm

[16] Saxenian, AnnaLee. Regional Advantage: Culture and Competition in Silicon Valley and Route 128. Cambridge, Mass.: Harvard University Press, 1994.

[17] TMC. "The History of Texas Medical Center". History of Innovative Medical Research. Updated $26^{\text {th }}$ April, 2019. https://www.tmc.edu/about-tmc/history/ 